This is a pre-copyedited, author-produced version of an article accepted for publication in The British journal of social work following peer review. The version of record Victoria Burton, Lisa Revell; Professional Curiosity in Child Protection: Thinking the Unthinkable in a Neo-Liberal World, The British Journal of Social Work, Volume 48, Issue 6, 1 September 2018, Pages 1508-1523 is available online at: https://academic.oup.com/bjsw/article/48/6/1508/4604651 and https:// doi.org/10.1093/bjsw/bcx123

Professional Curiosity

\title{
Professional Curiosity in Child Protection: Thinking the Unthinkable in A Neoliberal World
}

\section{Victoria Burton and Lisa Revell}

\section{$\underline{\text { Abstract }}$}

This conceptual paper explores the notion of professional curiosity within child protection practice considering the barriers that can inhibit social workers invoking curiosity. The authors contend that definitions of professional curiosity are lacking in clarity and transparency, at the time of writing we are not aware of any other endeavours to create a definitional reference point or analysis of this concept. Furthermore, invoking professional curiosity is challenging when the social work task is pressurised, stressful and operates within a system that is stretched to breaking point. Drawing on messages from Serious Case Reviews in the UK which identify social work failings in context of a lack of professional curiosity, this paper initially focuses on constructing some definitional reference point, moving on to explore factors that may inhibit curiosity in practice. We cement connections between the emotional dimension of child protection practice, organisational context and the wider neoliberal political climate, constructing these as potential barriers to invoking curiosity. We contend the interplay of such complicated relational dynamics has the potential to distort professional judgement, including enacting curiosity. Finally, we consider realistic mechanisms by which social workers could be supported to generate creativity and curiosity in their practice.

\section{Introduction}

The concept of 'professional curiosity' in relation to child protection practice is intriguing, arguably open to interpretation and lacking in defining characteristics. In a mirror image of the way in which the social work profession has been beset with flux, contradiction and 'longstanding tensions about it role and purpose' (Jones 2014b:285), the notion of professional curiosity in child protection practice appears to be both assumed and inextricably linked to the politics that surround the social work task itself. The social work identity is confused and contested with internal and external questions of confidence threatening the integrity of the profession (BASW 2015, Butler and Drakeford 2012, Ferguson 2011, Horner 2012, Jones 2014b, Jones 2014c, Laming 2009, Munro 2004, 2011, Parton 2014, Rogowski, 2010, Warner 2014, Younghusband 1981).

The phrase 'professional curiosity' began to permeate social work terminology and Serious Case Reviews circa 2013 and appears to reflect the language of the Professional Capability Framework (TCSW 2012); although it is difficult to be definitive regarding its origin, nor pinpoint why the phrase carries such currency at present. Recurrent messages emerging from contemporary Serious Case Reviews reinforce a perspective that a lack of sufficient curiosity had contributed to abuse going undetected, inferring that if professionals had been 'more curious', this may have unearthed information that would have prevented harm, as exemplified below; 
'There was a consistent lack of professional curiosity and challenge to both parents and other professionals, this contributed to poor assessment, lack of recognition of risk/vulnerability and subsequently poor ineffective management.' (Windibank 2014:27) Serious Case Review - Baby F Bexley Safeguarding Children Board

The notion of a failure to invoke professional curiosity also appears in the following Serious Case Reviews; Hamzah Kahn (Frost 2013:4), Daniel Pelka (Lock 2013:6), Keanu Williams (Lundberg 2013:8) and the Oxfordshire SCR regarding Child Sexual Exploitation (Bedford 2015:1).

Our starting point is to construct a definitional reference point, assembling characteristics that may constitute professional curiosity, before moving on to explore barriers to invoking curiosity in practice. Paying particular attention to the emotional dimension of child protection practice, we draw on the work of Cooper $(2005)$, Ferguson $(2011,2016)$ and Rustin (2005) to explore the intense, extreme and often unacknowledged emotional demands placed upon social workers in their daily practice encounters. We suggest this forms a central thread to the argument in tandem with the organisational context (Cooper 2005, Ferguson 2016, Reder and Duncan 1993) and the current neoliberal political position, asserting these are key factors hindering practitioner's ability to invoke curiosity in practice.

The death of Peter Connelly in 2007 and publication of the Serious Case Review in 2008 arguably became a defining moment creating a 'politization' of the profession (Butler and Drakeford 2012:1999, Parton 2014:69). The subsequent vilification of social workers exemplifies the destructive, politically motivated nature of the relationship between the social work profession and the media (Warner 2013). Social work became a professional scapegoat enabling society to displace blame, to avoid 'thinking the unthinkable' in the notion of child death and familial homicide (Shoesmith 2016). The looming spectre of a general election in 2010 meant Peter's death became a mechanism for political manoeuvring, forcefully marshalled by The Sun newspaper as relationships between the media and politicians allowed a simplistic, stereotypical narrative to dominate.

Extending this argument further, Featherstone et al (2014b:1736) suggest the high-profile coverage of child death contributes to conditions for the 'perfect storm', to reshape the profession. The ideological agenda did not only extend to winning a General Election, the neoliberal rhetoric of free market forces in which profit takes precedence and deep cuts to public spending have laid the foundations for privatisation. The former point combined with authoritative legal disposals emphasising early intervention and swift adoption policies have created the perfect position from which to reconstruct the profession. This does not create a climate conducive to encouraging curiosity, as embedding learning from Serious Case Reviews within such a hostile, reactive culture has become increasingly problematic (Rawlings et al 2014). This has contributed to an organisational context which is stretched to breaking point 
(NSPCC 2015, NSPCC 2014) as increasingly risk averse, neoliberal policies take hold (Jones 2014a).

Whilst the political context is not the primary focus of this paper, the authors argue it is inextricably linked to organisational culture, as it provides the backdrop to the changing social and political landscape, which filters down to individual practice encounters. Reference to this wider context punctuates the debate throughout. We assert that several factors align, firstly, the increase of inequality as a characteristic of contemporary society in which the vulnerable have become increasingly marginalised (Featherstone et al 2014b, Harvey 2005, Rogowski 2012, The Good Childhood Report 2014, Wilkinson and Pickett 2010). This has relevance for a value based profession such as social work; Rogowski articulates a long term, cumulative erosion of the professional value base, asserting 'the caring and supportive side of state social work does not fit in with neoliberal ideology' (2012:936). Secondly, the 'proceduralisation' of the profession as market forces take hold, creating risk averse practices dominated by performance management indicators and paperwork. This is exemplified by the move from 'need to risk,' in the pursuit of eradicating uncertainty to prevent and manage perceived risk. Thirdly, the 'proceduralisation' has in turn created a disconnect from frontline practice when the heart of social work is relational and emotional (Ferguson 2016, Ruch 2012). Featherstone et al (2014a, 2014b) offer strong support for this position, articulating the effects of neoliberalism and free market forces upon child protection practice; cautioning that a profession under attack translates in to defensive practice and underscores existing power imbalances on an individual level. We suggest the complex interplay of these factors undermine both the credibility and identity of the profession, and construct barriers to enacting professional curiosity.

\section{A Profession Under Pressure}

The pressurised context of contemporary child protection practice in the UK is welldocumented but it is useful to briefly consider the current climate in reference to an exploration of professional curiosity. Evidence continues to amass indicating that systems are buckling under pressure with demand outstripping resource, as referrals into the child protection system have increased year on year post 2008. This is set against a backdrop of increasing austerity and cuts to public spending (NSPCC 2016, NSPCC 2015, NSPCC 2014, Community Care 2013); As outlined by the NSPCC (2014:6) '...amid funding pressures and high demand for services, child protection is becoming more tightly "rationed".' Applications for Care Orders (Section 31, Children Act 1989) reached an all-time high of 14,579, between March 2016 and April 2017, compared with 6,323 applications between 2007/8 according to CAFCASS (2017) data. Numbers of children in care have risen steadily since 2008 (DfE 2016) and children subject to child protection plans or child protection registration similarly illustrates an increase over a five year period in all UK countries with the exception of Northern Ireland (NSPCC 2016). Paradoxically death rates relating to physical abuse and assault have fallen and are continuing to do so (NSPCC 2016, NSPCC 2014), whilst 
comparatively overall child death rates in the UK have also dropped significantly over the last 30 years (Fraser et al 2014).

Bilson and Martin (2016) gathered data on initial referrals into the children protection system via Freedom of Information Requests demonstrating significant increases in numbers of children subject to initial referrals, although this does not equate to the numbers offered a service. This upward trajectory has been climbing since 2008 as the impact of the 'Baby $P$ effect' continues to translate to increasingly defensive and risk averse practice in England, although Bilson and Martin (2016) suggest the pattern of increasing numbers of children involved in the child protection system is evident in other countries where understandings of child protection and maltreatment have expanded to consider well-being more widely.

\section{Professional Curiosity}

We contend that understandings of professional curiosity appear to be assumed and lacking in clarity; at the time of writing we are not aware of any other endeavours to understand the concept with greater precision and depth. We begin with assimilating a definitional reference point, placing this in context of the organisational and political climate using the work of Ferguson (2016) as a vehicle to explore these connections. A logical starting position is to construct an understanding of the characteristics that constitute professional curiosity, turning to psychological studies of curiosity offers some useful definitional perspective. Kashdan et al (2013:142) explain curiosity as an exploratory behaviour; '...the predisposition to recognize and search for new knowledge', with their study identifying that naturally curious people appear to possess a number of higher order skills including: flexibility, the ability to adapt to changing situations and '...enjoyment of complex and abstract thinking, strong intellectual capacity...comfort with uncertainty and anxiety'. Research underscores the difference between curiosity and other positive emotions, in that curiosity is characterised by growth, exploration and development (Berlyne 1954), as opposed to feelings that create only a sense of comfort and security, (Ainley 2002, Kashdan and Steger 2007, Turner and Silvia 2006). Curiosity could quite literally be described as 'stepping outside your comfort zone'; the essence of child protection practice.

Experiencing tension is a central element of a curious approach (Kashdan et al 2013, Litman and Jimerson 2004), suggesting that anxious thoughts and discomfort are a natural part of this process; again, a curious parallel with the emotional dimension of child protection practice. In her analysis of the Victoria Climbié Inquiry Report, Rustin (2005:11) suggests that of significance is the role of psychological defence mechanisms for workers in child protection cases. Understanding the way in which workers process such feelings is critical to understanding responses of evasion and inaction, which would seem to represent the opposite of professional curiosity, particularly when active parental deceit, or disguised compliance is taking place. Returning to understandings of curiosity, if avoiding the source of trauma is a natural defensive mechanism to uncomfortable feelings, this poses questions 
about how we prepare social workers to engage with tension, uncertainty and be emotionally astute enough to recognise this as a signal to push for further information.

The space occupied by this uncertainty and tension is essentially a core function of the child protection task; understanding gaps in knowledge and identifying discrepancy in parental stories about harm to children. Exploring the role of tension and uncertainty, Silvia (2006) offers a view that in order to engage in curious behaviour, the individual must believe that they can manage these tensions, working towards a reduction in discrepancy, which is associated with a decrease in feelings of tension. Lowenstein (1994) suggests that 'uncertainty reduction' is one of the core functions of engaging in curious behaviour, an important factor for social workers linked to reflective practice and supervisory processes. For social workers, how they are supported to understand these discrepancies is a key consideration; situations which lack in congruence are ever-present in social work practice and this has relevance in regard to organisational and political context. Arguably, to invoke professional curiosity, practitioners need to have some confidence that whatever they unearth including their own feelings of horror, fear and despair, will be managed (Revell \& Burton 2015).

This represents the connection between practitioners, their managers and the work they undertake, which is embodied within reflective practice and supervisory relationships. This is perfectly illustrated by Ferguson (2016: 8-11) within his ethnographic research via discussion of the 'Brown' family. The social worker in this case had no time or space to emotionally prepare for the hostility and resistance presented during a home visit, and was preoccupied by office duties, creating a situation in which Ferguson asserts the child became 'seen but not seen'. What seems significant is that within the context of the overall study, this social worker's practice had been observed on other occasions as competent, suggesting there was something about this particular encounter which suffocated her ability to be curious and exploratory.

Ferguson (2016) argues such situations create detachment from the child, parent, the practice context and crucially from the ability to engage in critically reflective practice which would allow for re-evaluation of knowledge and information gained, which in turn may help identify discrepancies. Marshalling links to organisational contexts, Ferguson (2016) describes how social workers in his study became overwhelmed by a combination of the complexity, emotional intensity and organisational demands, including time limits and a lack of support. There was no opportunity in the Brown case for 'uncertainty reduction' as suggested by Lowenstein (1994); there was no planning for the visit, no post visit debrief, no supervisory reflective process that would mitigate the impact of the visit. Without the reflective space to manage tension and hostility the child is lost from sight, creating the perfect conditions for a child to be 'seen yet not seen' and for harm to go undetected.

Ferguson (2016:13) describes such detachment as being 'bureaucratically preoccupied.' A climate is created whereby curiosity is stifled, and exploratory, inquisitive behaviours 
designed to identify discrepancy are not accessible, placing distance between the worker and the child. This resonates with the argument articulated by Featherstone et al (2014a, 2014b) regarding a disconnect from frontline practice. This creates distance between social workers and service users, exaggerating existing power imbalance whilst simultaneously shifting the goalpost towards a more bureaucratic, prescriptive approach less likely to engender curiosity in practice. This provides a catalyst into consideration of the wider political context, the performance management agenda and the 'electronic turn' as these components form the hub of the 'proceduralisation' of the profession.

The accelerated descent into managerialism and performance management was to become a defining feature of social work practice under the helm of New Labour (Harris and White 2009) derived from a business model in pursuit of profit. The 'electronic turn' began to seep insidiously into daily social work practice, eroding and minimising the time spent in face to face encounters, influencing the nature of front line social work practice (Garrett 2005:542, White et al 2010). The move away from assessment of need, to assessment of risk is a significant feature in the neoliberal world of social work and has produced spurious increases in the documentation required, without necessarily leading to actual benefits or interventions for children and families (Rogowski 2010). Revisions to the Framework for Assessment (2000) provide a clear example of this. The paperwork, not the person, takes precedence, and simultaneously gets in the way of seeing, feeling and experiencing the emotions and dynamics that are part and parcel of the child protection intervention, again emphasising the notion of distance. Blame culture has continued to thrive and eliminating potentially fatal levels of risk becomes the focus for inquiry with emphasis placed upon protecting organisational reputation (Rogowski 2012:934). Borrowing from Warner (2013: 1638) she asserts this '...can be understood less as a means of managing risk and more as a (dysfunctional) means of managing anxiety about risk'.

Returning to understandings of curiosity, it is unsurprising that in such adversarial and defensive conditions some social workers may struggle to invoke curious and inquisitive practice; they become overwhelmed with the complex emotional and organisational demands placed upon them. This can create a potent set of variables as illustrated by Ferguson (2016:14), which can create the conditions for a child to become invisible;

'...how children become invisible...is not reducible simply to 'bad' practitioners, but must be understood in terms of the interaction of organisational processes, the practitioner's qualities, their visceral experience and emotional state during face-toface encounters'

We now turn our attention to exploration of barriers to invoking curiosity, initially discussing the emotional dimension of child protection practice, moving on to consider the role of knowledge and experience in decision making processes.

Barriers to Curiosity - The Emotional Dimension of Child Protection Practice 
"We see things not as they are, but as we are"

Immanuel Kant (cited in Serious Case Review for Daniel Pelka CSCB 2013:71)

Child protection practice represents the interface between public and private sphere and as such, practitioners are the conduit for tales of trauma, distress, anger and denial on a regular basis. If curiosity is constructed as an emotional response, this has resonance with the emotional dynamic of child protection work and furthermore, the capacity for practitioners to believe such discomfort and uncertainty is manageable. The latter point will be dependent on various individual and organisational factors (McFadden 2014), however, we seek to contend that the emotional dimension of the work can be constructed as a potential barrier to invoking professional curiosity. On an individual level, workers are forced to confront the possibility of harm to children and along with this the myriad of personal feelings that they may experience, generating tension or a state of cognitive dissonance by managing or holding different, conflicting perspectives.

Cooper (2005:8), in the context of his analysis of the Victoria Climbie case and subsequent Serious Case Review by Lord Laming, asserts that the result is often an emotional disconnect from the source of the stress; 'In ordinary language we call this 'turning a blind eye'. With one part of our mind we take in what is happening, but with another, we repudiate what we have seen'. Reder et al (1993:107) refer to this as the 'not exist' or 'double bind' in relation to parental deception, citing the case of one-year-old Malcolm Page in the final weeks of his life, suggesting: 'it was as though he had ceased to exist' (Reder et al 1993:108). Examples of the 'not exist' concept also punctuate the case of four-year old Daniel Pelka who died on 3rd March 2012. Despite being a regular school attender, Daniel's experiences were distorted through the lens of his abusive, manipulative parents, who were actively and successfully engaged in the processes of deceit with multiple professionals, including social workers. Both Daniel and the harm he was suffering became invisible. The last six months of Daniel's life represented a significant increase in the abuse and neglect he was experiencing, including marked weight loss and patterns of bruising. The Serious Case Review asserts;' ...if practitioners were not able to accept that abuse existed for Daniel, then they would not see it' (2013:71). Again, the concept of distance or disconnect resonates strongly, only this sense of disconnect is located on an individual level between the practitioner and parents or children.

The emotional dimension of child protection practice has been carefully deconstructed by Ferguson (2011:132) who utilises the work of Cohen (2001) to try and explain the complex processes at work in the Victoria Climbié case:

'These professionals were caught in the midst of what Cohen calls 'the dynamics of knowing and not knowing'. They became bystanders to an appalling atrocity. They knew but they didn't know what was happening to Victoria and did nothing...This is another example of the avoidant behaviour professionals engage in when faced with intolerable 
feelings stirred up by having to think the unthinkable about what may have been done to a child'. Ferguson (2011:132)

This extract is in reference to a hospital admission, when Victoria had been bathed and as many as five nurses noticed substantial injuries to her body, including a bruised and swollen arm and possible belt marks. These concerns were not recorded in the notes, despite Victoria being highlighted as a child protection case; the nurse could give no reason for why she did not do so. Ferguson notes that 'similar examples could be given for social workers, the police and housing officials in the Climbié case' (2011:132) asserting professionals did not appear to 'see' what was before them, or quite simply in relation to the Victoria Climbié enquiry, were unable to 'explain their inaction'. Translating what is 'known but not known' into action becomes impossible in such circumstances and whilst children are rendered invisible or silent by those who harm them, professionals fall foul of the same powerful dynamics.

Drawing on systems and psychodynamic theory to explain such behaviours, Ferguson (2011) posits a powerful argument to explain the failure to act in this example relating to Victoria; professional systems can come to mirror the families and individuals that they are seeking to engage with, as practitioners subconsciously and unwittingly absorb the child's feelings, but rarely recognise this as such. The desire to disconnect from such revulsion and fear is an instinctive one, a protective mechanism to repress 'unbearable feelings'. Ferguson (2016) argues this has particular significance in organisational cultures that do not help practitioners openly manage the emotional dimension of such work as discussed previously, within the concept of becoming 'bureaucratically preoccupied'. In Victoria's case, the office dynamics were noted to be problematic, with a culture of working long hours at a fast pace, and to some extent this is mirrored in the Serious Case Review for Hamzah Kahn when the authors refer to difficult working conditions (Frost 2013:7) and the impact this will have in terms of creating conditions conducive to invoking professional curiosity.

This represents a disconnect between individual practice and the wider social work context; if the emotional dimension of child protection practice and the organisational context are viewed as relational, then it does go some way to understanding why, on some occasions, some frontline practitioners simply do not see what is happening in front of them. Using the work of Cooper (2005:4) as a mechanism to explore this further, he argues there is a fundamental incongruence between 'policy aims and practice realities' which manifests as a lack of understanding of the emotional complexities and realities of child protection practice. He articulates a level of cynicism in which research does not fully engage with the depth required to understand social work practice responses, failing to address such basic questions around how social workers process referral information, make sense of the work and engage in complex decision making processes. Cooper's analysis of the Victoria Climbié Serious Case Review argues that Serious Case Review reports are in danger of sanitizing the horror, misery and profound trauma that children suffer and the substance required to understand such complex phenomenon is absent; 
'The events recounted in its pages constitute a story or network of stories with many missing dimensions, connections, lost threads, and silences. The stories are factually coherent, but also radically incomplete' (Cooper 2005:4).

Ferguson $(2011,2016)$ supports this view asserting we need more 'near practice research' in real time as opposed to retrospective discussion and detailed consideration of the mechanics of child protection practice which 'captures the humanity of the experience' (2011:4). Analysis of these processes in his 2016 study is enlightening in understanding the inter-relationship between the complex emotional and organisational dynamics at play. Far from being extraordinary events, it appears that it is the ordinary day-to-day demands of the job that in certain situations, create the conditions for children to be 'seen but not seen'.

The emotional dimension of child protection practice is precisely the element that can cause distortion, uncertainty and confusion, yet is invariably absent from discussion and Serious Case Review Reports. The powerful and often unacknowledged emotional content of exchanges between social workers and families becomes a significant barrier to curious and exploratory behaviour in these contexts and is rendered invisible in the same manner children's experiences of abuse and harm are (Reder and Duncan 1993). There are questions about how we help social workers learn, practice and rehearse complex skills in such emotionally demanding contexts and arguably, the need for an emotional curriculum for students and social work practitioners to continue to develop and hone these skills. Importantly, the individual context cannot be detached from the organisational context and questions remain about how effectively the system supports social workers to deal with the emotional dimension of the work (Revell and Burton 2015, McFadden 2015) via reflective space and good quality supervision, particularly as the system becomes more pressurised.

\section{Knowledge and Experience as Barriers to Curiosity}

Openness to new knowledge has been highlighted as a critical factor in identifying potential harm to children (Akister 2011, NSPCC 2010) suggesting a failure to adapt to new knowledge, or re-examining pre-existing hypotheses can lead practitioners to make incomplete judgements, decisions and assessments. Akister (2011:315) underscores how limitations in knowledge can influence interpretation and perception of maltreatment, referring to the concepts of 'thinking the unthinkable' and 'openness' as key practice points, outlining how practitioners must 'think beyond their previous experience'. This resonates with understanding curiosity as exploratory and inquisitive, to push beyond the limits of knowledge and experience could be considered as both complex and anxiety provoking, yet potentially transformative in terms of understanding the reality of a child's situation.

This adds an additional potential barrier to enacting curiosity which seems to mirror notions of 'confirmation bias' (Sheppard, 2006) in that we are drawn to what we know. If the knowledge base is limited this can be problematic as it will constrain what is 'seen' and hinder identification of harm to children, leading to superficial understandings and assessments which do not reflect reality; contributing to situations in which children are 'seen but not 
seen'. Furthermore, Akister (2011:315) asserts 'observation is influenced by what we expect to see' which in turn is influenced by multiple factors including knowledge, values and beliefs, inclusive of the emotional and organisational dynamics as illustrated in previous discussion via the work of Ferguson (2016). What we observe is filtered through our own subjective lens and we are reminded of the words of Immanuel Kant; 'We see things not as they are, but as we are' (p6).

Akister (2011) extends this further by alluding to the central tension in safeguarding practice and the dichotomous nature of relationships whereby developing trust with parents is essential to the task, whilst simultaneously exercising mistrust. The manifestation of tension is a central concept in relation to our discussion regarding curiosity (page 4) and also appears to be important in regard to limitations of knowledge and experience. This has some resonance with other characteristics of curiosity as suggested by Kashdan et al (2013) including the necessity for higher order skills including flexibility, adaptability and a desire to look for new knowledge which synthesise with the importance of retaining openness to new knowledge (Akister, 2011). Again, the safety valve is reflective practice and external scrutiny of practice via supervisory processes and training to engender rigorous practice. The significance of good quality supervisory relationships that can withstand challenge cannot be underestimated in such circumstances.

\section{Conclusion}

Arguably, 'professional curiosity' has become a social work 'buzzword', gaining in both currency and credence, yet with little real understanding of its meaning and concept. At the time of writing, the authors are unaware of any other endeavours to create a definitional framework regarding professional curiosity and it is anticipated that this paper will become a catalyst for discussion, debate and practice. We have assembled some of the characteristics that may constitute professional curiosity and have argued that a reductionist approach to understanding failures to enact curiosity is problematic. Invoking curiosity represents a complex inter-relationship between self, organisational and political context, these combined factors create a potent set of variables which are constructed as potential constraints to invoking curiosity in practice.

Enabling practitioners to invoke curiosity in practice is a complex, nuanced process which appears to be inherently linked to the emotional dimension of child protection practice. In the same manner in which Cooper (2005) describes the report regarding the death of Victoria Climbie as 'sanitized' of emotional content, we argue that understandings of professional curiosity cannot be detached from the emotional nature of the task - failure to do so represents a flawed approach. Given the role of emotion is arguably pivotal to robust child protection practice, consideration of an 'emotional curriculum' (Grant, Kinman and Alexander 2014) both during training and post-qualification would seem to represent a logical starting point, alongside more traditional assessment of cognitive and academic abilities. Furthermore, the complex nature of the work needs to be considered alongside the 
pressurised organisational and political context which is not always conducive to reflection, analysis and creating space for practitioners to consider the emotional dynamic of the work as illustrated by Ferguson (2016).

Tension is constructed as one of the central characteristics of curiosity within the psychological literature and working with multiple tensions is one of the most challenging aspects of the social work task. We contend this translates to a greater focus on the emotional content of the work and the relational element of supervision which is problematic in a wider climate which appears to be creating distance, or disconnect, between service users, practitioners and their managers. The literature suggests that confidence in managing tension is also a critical factor to invoking curiosity, yet set against the current political and economic backdrop with a predominant focus on performance management targets, there seems to be little room for optimism. In the current climate, these are challenging matters to consider which have implications for social workers at all levels of seniority; including social work qualifying programmes, supervisors and strategic managers as this is alluding to a cultural shift.

Perhaps of interest here is that despite the high levels of stress associated with the role, the work can be transformative, which synthesises with understanding curiosity as transformative (Kashdan and Steger 2007). The emotional toil is precisely the element of practice that can lead to distorted understandings and a lack of curiosity. With the right support, supervision and analysis, it is also the component of the work that has potential to bring great reward and satisfaction, and arguably, the capacity to move closer towards a deeper understanding of the challenging and complex nature of child protection casework.

\section{References}

Ainley, M. \& Hidi, S. (2002) Dynamic measures for studying interest and learning, in P.R. Pintrick and M. L. Maehr (Eds) Advances in Motivation and Achievement: New Directions in Measures and Methods, (p43-76) Amsterdam: JAl.

Akister, J. (2011) Protecting Children: The Central Role of Knowledge, Practice: Social Work in Action, 23:5, $311-323$.

BASW (2012) Code of Ethics, London: BASW.

Bedford, A. (2015) Serious Case Review into Child Sexual Exploitation in Oxfordshire: from the experiences of Children $A, B, C, D, E$, and $F$, Oxfordshire Safeguarding Children Board: Oxford.

Berlyne, D.E. (1954) 'A Theory of Human Curiosity', British Journal of Psychology, 45, 180 191. 
Bilson, A. \& Martin, K.E. (2017) Referrals and Child Protection in England: One in Five Children Referred to Children's Services and One in Nineteen Investigated before the Age of Five, British Journal of Social Work, 47 (3): 793-811.

Blyth, M. (2014) Moving on From Munro: Improving Children's Services, Bristol: Polity.

Butler, I. \& Drakeford, M. (2011) Social Work on Trial: The Colwell Inquiry and The State of Welfare, Bristol: Policy Press.

CAFCASS (2017) May 2017 Care demand statistics accessed at https://www.cafcass.gov.uk/leaflets-resources/organisational-material/care-and-privatelaw-demand-statistics/care-demand-statistics.aspx

Cooper, A. (2005) 'Surface and depth in the Victoria Climbie Inquiry Report', Child and Family Social Work, 10, 1 - 9.

Department for Education (2017) National Statistics: Children looked after in England including adoption: 2015 to 2016, London: DfE.

https://www.gov.uk/government/statistics/children-looked-after-in-england-includingadoption-2015-to-2016

Featherstone, B., White. S, \& Morris, K. (2014a) Re-Imagining Child Protection; Bristol: Policy Press.

Featherstone, B., Morris, K. \& White. S. (2014b) 'A Marriage Made in Hell: Early Intervention Meets Child Protection', British Journal of Social Work, 44, 1735 - 1749.

Ferguson, H. (2011) Child Protection Practice, Basingstoke: Palgrave Macmillan.

Ferguson, H. (2016) How Children Become Invisible in Child Protection Work: Findings from Research into Day-to-Day Social Work Practice, British Journal of Social Work, 0, 1-17.

Fraser, J, Sidebotham, P, Frederick, J., Covington, T. \& Mitchell, E.A. (2014) 'Child Death in High Income Countries 1 : Learning From Child Death Review in the USA, England, Australia, and New Zealand'; The Lancet, Vol 384, $894-903$.

Frost, N. (2013) A Serious Case Review; Hamzah Kahn, Bradford Safeguarding Children Board, Bradford: BSCB.

Garrett, P. (2005) 'Social Work's 'Electronic Turn': Notes on the Deployment of Information and Communication Technologies in Social Work with Children and Families', Critical Social Policy, 25 (4), $529-553$.

Garrett, P. (2009) 'The Case of 'Baby P': Opening up Spaces for debate on the 'transformation' of Children's Services?', Critical Social Policy, 29 (3), $533-547$. 
Grant, L., Kinman, G. \& Alexander, K. (2014) What's All this Talk About Emotion? Developing Emotional Intelligence in Social Work Students, Social Work Education, Vol 33, 874 - 889.

Harris, J. \& White, V. (2009) Modernising Social Work: Critical Considerations, London: Policy Press.

Harvey, D. (2005) A Short History of Neoliberalism, Oxford: Oxford University Press.

Horner, N. (2012) What is Social Work? Exeter: Learning Matters.

Howe, D. (2008) The Emotionally Intelligent Social Worker, Basingstoke: Palgrave Macmillan.

Jones, R. (2014a) The Story of Baby P - Setting the Record Straight, Bristol: Polity.

Jones, R. (2014b) 'The Best of Times, the Worst of Times, Social Work and It's Moment', British Journal of Social Work, 44, 485-502.

Jones, R. (2014c) Child Protection: Forty years of Learning, but where next? In (Eds) Blyth, M. (2014) Moving on From Munro: Improving Children's Services, Bristol: Polity.

Kashdan, T., Sherman, R.A, Yarbro, J. \& Funder, D. (2013) 'How Are Curious People Viewed and How Do They Behave in Social Situations? From the Perspectives of Self, Friends, Parents and Unaquainted Observers', Journal of Personality, 141 - 155.

Kashdan, T. \& Steger. M.F. (2007) 'Curiosity and Pathways to Well-being and Meaning in Life: Traits, States and Everyday Behaviours', Motivation and Emotion, 31, 159 - 173.

Kashdan, T., Rose, P. \& Fincham, F. (2004) 'Curiosity and Exploration: Facilitating Positive Subjective Experiences and Personal Growth Opportunities', Journal of Personality Assessment, 82 (3), $291-305$.

Laming, H. (2003) The Victoria Climbie Inquiry: Report of an Inquiry by Lord Laming, London: HMSO.

Litman, J.A. \& Jimerson,.T.L. (2004) The measurement of curiosity as a feeling of deprivation, Journal of Personality Assessment, 82, 147 - 57.

Lock, R. (2013) Serious Case Review into the death of Daniel Pelka, Coventry: Coventry Safeguarding Children Board.

Lowenstein, G. (1994) The Psychology of Curiosity: A Review and Reinterpretation, Psychological Bulletin, 116, 75 - 98.

Lundberg, B. (2013) Serious Case Review: In respect of the death of Keanu Williams, Birmingham: Birmingham Safeguarding Children Board.

McFadden, P. (2015) Measuring Burnout among UK Social Workers: A Community Care Study, Queens University Belfast: Belfast.

McFadden, P., Campbell, A. \& Taylor, B. (2015) Resilience and Burnout in Child Protection 
Social Work: Individual and Organisational Themes from a Systematic Literature Review, British Journal of Social Work, 45, 1546-1563.

Myers, J. \& Carmi, E. (2016) The Brooke Serious Case Review into Child Sexual Exploitation, Bristol: Bristol Safeguarding Children Board.

Munro, E. (2004) The Impact of Audit on Social Work Practice, British Journal of Social Work, 34 (8), 1075 - 95.

Munro, E. (2005) A Systems Approach to Investigating Child Abuse Deaths, British Journal of Social Work, 35, $531-546$.

Munro, E. (2010) The Munro Review of Child Protection: Interim Report: The Child's Journey, London: Department for Education.

Munro, E. (2011) The Munro Review of Child Protection: Final Report: A Child Centred System, London: Department for Education.

NSPCC (2013) How Safe are our Children? London: NSPCC.

NSPCC (2014) How Safe are our Children? London: NSPCC.

NSPCC (2016) How Safe are Our Children? London :NSPCC.

Parton, N. (2014) The Politics of Child Protection, Basingstoke: Palgrave Macmillan.

Rawlings, A. ,Paliokosta, P., Maisy, D., Johnson, J. \& Jones, R. (2014) A Study to Investigate the Barriers to Learning from Serious Case Reviews and Identify Ways of Overcoming these Barriers, London: Department for Education.

Reder, P. \& Duncan, S. (1993) Beyond Blame Child Abuse Tragedies Revisited, BrunnerRoutledge: London.

Revell, L. \& Burton, V. (2015) Supervision and the Dynamics of Collusion: A Rule of Optimism? British Journal of Social Work, 1-15.

Rogowski, S. (2010) Social Work: The Rise and Fall of a Profession? London: Polity Press.

Rogowski, S. (2013) Critical Social Work with Children and Families, London: Polity Press.

Rogowski, S. (2012) Social Work with Children and Families: Challenges and Possibilities in A Neo-Liberal World, British Journal of Social Work, 42, 921 - 940.

Ruch, G. (2012) Where Have All the Feelings Gone? Developing Reflective and RelationshipBased Management in Child-Care Social Work, British Journal of Social Work, 42, 7, 13151332.

Rustin, M. (2005) Conceptual analysis of critical moments in Victoria Climbie's life, Child and Family Social Work, 10, 11 - 19. 
Sheppard, M. (2006) Social Work and Social Exclusion, London: Ashgate Publishing.

Shoesmith, S. (2016) Learning from Baby P: The politics of blame, fear and denial, Bristol: Polity Press.

Sidebotham, P., Fraser, J., Fleming, P., Ward-Platt, M. \& Hain, R. (2014) Child Death in High Income Countries 2: Patterns of Child Death in England and Wales, The Lancet, Vol 384, $904-$ 914.

Sidebotham, P., Fraser, J., Covington, T., Freemantle, J., Petrou, S., Pulikottil-Jacob, R., Cutler, T. \& Ellis, C. (2014) Child Death in High Income Countries 3: Understanding why Children die in high income countries, The Lancet, Vol 384, 915 - 927.

Silvia, P.J. (2006) Exploring the psychology of interest. New York : Oxford University Press.

Smith, R. (2005) Values and Practice in Children's Services, Basingstoke: Palgrave Macmillan. TCSW (2015) Announcement: Closure of The College of Social Work, http://www.tcsw.org.uk/ The Children's Society (2012) How Happy are Our Children? Measuring children's wellbeing and exploring economic factors, London: The Children's Society.

Turner, S. A. Jr., \& Silvia, P. J. (2006). Must interesting things be pleasant? A test of competing appraisal structures. Emotion, 6, 670-674.

UNICEF (2007) Child Poverty in Perspective: An Overview of child wellbeing in rich countries, Innocenti Report Card 7, Florence: Unicef Innocenti Research Centre.

Warner, J. (2013) 'Heads Must Roll'? Emotional Politics, The Press and the Death of Baby P, British Journal of Social Work, 44 (6), $1637-1653$.

White, S., Wastell, D., Broadhurst, K. \& Hall, C. (2010) When Policy O'erleaps itself: The tragic tale of the Integrated Children's System, Critical Social Policy, 30, 405 - 29.

Windibank, O. (2013) Serious Case Review - Baby F, Bexley: Bexley Safeguarding Children Board.

Wilson, K. \& Pickett, R. (2010) The Spirit Level: Why Equality is Better for Everyone, London: Penguin.

Younghusband, E. (1981) The Newest Profession, Sutton: Community Care. 
Professional Curiosity 